\title{
HIGH PREVALENCE OF HBsAg CARRIERS IN A SPECIFIC COMMUNITY IN BULGARIA
}

\author{
Zahariy Krastev ${ }^{1}$, Ivan Stoev $^{2}$, Deian Jelev ${ }^{1}$, Aneta Ivanova ${ }^{1}$, Krasimir Antonov ${ }^{1}$, \\ Luydmila Mateva ${ }^{1}$ \\ 1) Clinic of Gastroenterology, St. Ivan Rilsky University Hospital, Sofia, \\ Bulgaria \\ 2) General Practitioner in village of Ablaniza, Bulgaria
}

\begin{abstract}
Objective: $\mathrm{HBV}$-infection is intermediate-endemic in Bulgaria. There is a trend for decreasing of HBsAg-carrier rate in the last decades, but prevalence remains higher in some specific ethnic communities. Current data regarding high-endemic sources of HBV-infection are limited.

Methods: HBsAg and anti-HCV were tested in 677 subjects from a specific ethnical community: 413 adults and 264 adolescents, covered by the National Program for HBVvaccination of all newborns.

Results: Thirty-two of adults $(7,7 \%)$ were HBsAgpositive. The observed HBsAg-carrier rate was more than three folds higher than general Bulgarian population. In contrast only $2 / 264(0.7 \%)$ of adolescents were HBsAgpositive. They both were born from HBsAg-positive mothers. Anti-HCV-positive subjects have been found neither among adults nor among adolescents.

Conclusion: Our results confirmed existence of separate high-endemic sources of HBV infection in Bulgaria. HBV vaccination program is highly effective even in such specific subgroups and resulted in marked decrease of HBsAg-carrier rate among adolescents.
\end{abstract}

Key words: HBV epidemiology, HBsAg prevalence, ethnical groups, HBV vaccination

\section{INTRODUCTION}

Hepatitis B is intermediate-endemic in Bulgaria, but in the last two decades there is a trend for decreasing of HBsAg carrier rate. This rate was $5.1 \%$ in 1987 for blood donors in Sofia and 3.9\% for the total population in 1999 $(1,2)$. In 2007 only $2.2 \%$ of blood donors in Sofia were HBsAg-positive (3).

The epidemiological data clearly suggested the positive impact of the National Vaccination Program, started in 1991 with mandatory vaccination of all newborns (4). The coverage rate of vaccination in Bulgarian neonates in 1992 and 2001 was $71 \%$ and $93 \%$, respectively $(2,4)$. One year after the introduction of vaccination against HBV a dramatic decline in the reported annual incidence of acute hepatitis
$B$ in infants was seen (4). In addition 10 years after implementation of $\mathrm{HBV}$ vaccination program there was a decrease in the incidence of acute hepatitis B cases in all age groups, but the most demonstrative results was found in the age group of 5-14 years (2).

Nevertheless, the prevalence of HBsAg carriers still remains higher in some specific ethnic communities compared to general population. Current data regarding high-endemic sources of HBV infection in our country are still limited and the actual impact of implemented total HBV vaccination of all new bourns remains unknown in such specific communities.

\section{MATERIALS AND METHODS}

Prevalence of HBsAg carrier rate was studied in a specific ethnical community of peoples (Bulgarian Mohammedans) living in village of Ablaniza. This place is situated in South-Western part of Bulgaria and was selected for the present study as over the years a number of patients with HBV infection, living in this village, were referred to the Clinic of Gastroenterology, St Ivan Rilsky University Hospital in Sofia for further follow-up and treatment.

In January 2011 blood samples were obtained from the inhabitants of Ablaniza who were willing to check their serological status for HBsAg and anti-HCV. No selection of studied population has been performed prior the collection of blood samples. Six hundred and seventy-seven subjects were tested. They were divided in two groups: 413 adults and 264 adolescents. All adolescents were born after 1992, i.e. after implementation of the National Vaccination Program for total HBV vaccination of all newborns. HBsAg and anti$\mathrm{HCV}$ were measured by HBsAg and anti-HCV cassette test (CE, in-vitro diagnostic use).

\section{RESULTS}

Thirty-two out of 413 adult subjects (7.7\%) were $\mathrm{HBs} A g$-positive, indicating high endemic prevalence of $\mathrm{HBV}$ among inhabitants of studied village. In contrast $\mathrm{HBsAg}$ carrier rate was very low $(0.7 \%)$ among adolescents (fig 1$)$. 


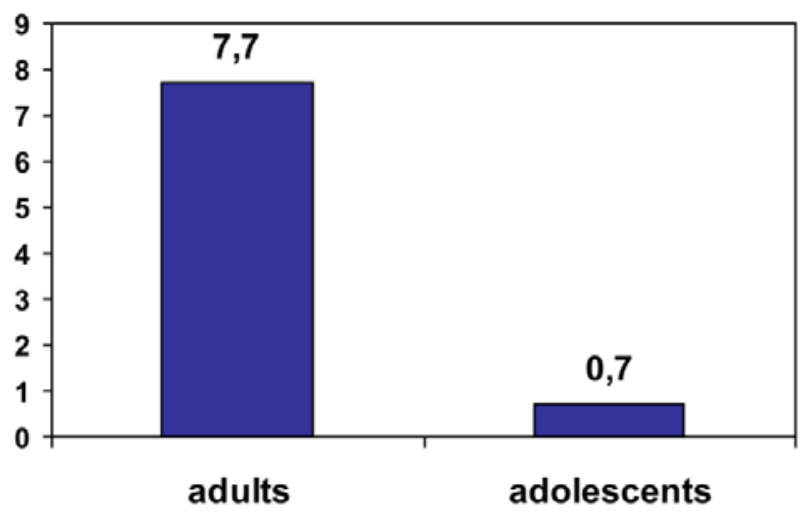

Figure 1. HBsAg-positive rate (\%) among adults and adolescents in village of Ablaniza.

Only 2 out of 264 adolescents were HBsAg-positive. They both were born from HBsAg-positive mothers.

Anti-HCV-positive subjects have been found neither among adults nor among adolescents.

\section{DISCUSSION}

The observed HBsAg carrier rate among adults was more than three folds higher than general Bulgarian population. The exact reasons for this high HBV prevalence are unknown. Drug abuse is not a problem in the discussed community and probably this is the reason for absence of $\mathrm{HCV}$ infection in the studied population.

Infected saliva might be an important vehicle of infectivity in such communities. In the previous study we detected HBV DNA in saliva by high-sensitive real-time PCR assay even in subjects with low viral load (5). In addition ritual circumcision of boys might have a role for horisontal HBV transmission in the past (6).

However, even in this high - endemic community the prevalence of HBV infection decreased significantly among adolescents after introduction of total vaccination of all newborns. HBV vaccination is not the only factor related to the observed decline in HBsAg carrier rate. The role of improved hygienic conditions during the last years, introduction of single-used syringes and medical equipment as well as better control of blood products is of great importance, too.

Our finding that two HBsAg positive adolescents in this high - endemic population were born from HBsAgpositive mothers is quite important. In Bulgaria HBIG is still not wildly available and unfortunately is not routinely used in high - risk newborns of HBsAg-positive mothers. It was well established that application of HBIG immediately after delivery plus HBV vaccination is associated with significantly lower risk of HBV transmission from mother to baby $(7,8)$.

\section{CONCLUSIONS}

Our results confirmed the existence of separate highendemic sources of HBV infection despite of decreeing prevalence of HBsAg carriers in general Bulgarian population. HBV vaccination program is highly effective even in such specific subgroups and resulted in marked decrease of HBsAg carrier rate among vaccinated adolescents.

\section{ACKNOWLEDGMENTS:}

Authors thank to all teachers and staff of Community School in Ablaniza for their help and kind technical support in organizing and conducting of this hepatitis $\mathrm{B}$ and $\mathrm{C}$ community testing campaign.

\section{REFERENCES:}

1. Gubev E, Rashkov R, Dimitrova T, Sharankov N, Andonov A. [Comparative studies of the distribution of hepatitis B markers among blood donors and patients with post-transfusion hepatitis in the city of Sofia]. Vutr. Bolesti 1987; 26(3): 38 - 43. (in Bulgarian) [PubMed]

2. Kojuharova M, Kourtchatova A, Eurohep.net team. Surveillance, epidemiology and prevention of Hepatitis B in Bulgaria: results of the EUROHEP.net feasibility survey. www.eurohep.net/2001/
3. Krastev Z, Jelev D. Hepatitis B virus infection in Bulgaria. VIII National Congress of Infectious Diseases, 16-18 October 2008, Sofia, Abstract Book: 19 - 22. (in Bulgarian)

4. Gatcheva N, Vladimirova N, Kourtchatova A. Implementing universal vaccination programs: Bulgaria. Vaccine 1995; 13 (Suppl 1): S82 - S83. [PubMed]

5. Ivanova A, Krasteva A, Panov V, Jelev D, Antonov K, Krastev Z. Is saliva dangerous in transmission in HBV hepatitis? Gut 2008; 57 (Suppl. II): A288. (Abstract)
6. Alter MJ. Epidemiology of hepatitis B in Europe and worldwide. J Hepatol. 2003, 39 Supl 1:S64-9. [PubMed]

7. EASL. Clinical Practice Guidelines: management of chronic hepatitis B. J Hepatol., 2009 Feb;50(2): 227-42. DOI: 10.1016/j.jhep.2008.10.001 CrossRef] [PubMed]

8. Lok AS, McMahon BJ. Chronic Hepatitis B: AASLD Practice Guidelines. Hepatology, 2007 Feb;45(2): 507-539. DOI: 10.1002/hep.21513 CrossRef] [PubMed]

\footnotetext{
Address for correspondence:

Dr. Deian Jelev

Clinic of Gastroenterology, St. Ivan Rilsky University Hospital,

15, Acad. Ivan Geshov Blvd., Sofia 1431, Bulgaria

phone: + 3592952 6319; fax: +35928510816

E-mail:dejelev@yahoo.com
} 